\title{
PRIMARY GLAUCOMA AMONGST GOLD COAST AFRICANS*
}

BY

\author{
J. W. R. SARKIES \\ Gold Coast Hospital, Accra
}

Glaucoma has been reported to be common in many tropical countries, observations having been based on various criteria. Elliot (1920) noted that in the Madras Eye Hospital the proportion of surgical operations for glaucoma and cataract were in the ratio of one to four. Chang (1951) reported that 1.75 per cent. of 13,807 ophthalmic out-patients in Peking suffered from primary glaucoma. Dodds (1952) found that glaucoma was the cause of blindness in 20 per cent. of 356 patients at the Lagos Eye Clinic. Budden (1952) in Northern Nigeria found that, in just under 3 per cent. of 144 persons blind in both eyes, the cause was glaucoma. Boase (1952) has commented on the frequency with which chronic primary glaucoma is seen in Uganda, and he emphasizes the youth of some of his cases.

During the past 3 years the writer has noted an apparent high incidence of chronic primary glaucoma amongst Gold Coast Africans. However, analysis of 2,312 consecutive out-patients drawn mainly from urban populations, who attended the Ophthalmic Department of the Gold Coast Hospital in Accra, showed that 49, or a little over 2 per cent. were suffering from chronic primary glaucoma. The ratio of filtration operations for glaucoma to cataract extractions during one year was $55: 153$. There is no blind registration in the Gold Coast, but 45 (approximately 19 per cent.) of 241 patients blind in both eyes from the same cause when first seen were suffering from chronic primary glaucoma.

The characteristics of chronic glaucoma amongst Africans differ little from those seen amongst Europeans. Two features necessitated certain further investigations before a rational study could be made. Concomitant hypertension with primary glaucoma appeared to be extremely common in Gold Coast Africans, and it was necessary to obtain a normal for the population. Language difficulties and the natural politeness of the patients, whose primary aim seems to be to please the doctor, make the results of campimetry confusing. Diagnosis often rests on the findings of repeated tonometry. It was therefore necessary to establish a basic average intra-ocular tension and response to provocative tests. With these objects in view, a preliminary investigation was carried out on a Control Group "A ", consisting of 81 African clerical employees in Government offices in Accra who

* Received for publication March 25, 1953. 
were over the age of 40 years. Blood pressures only were recorded in a second Control Group “B”, consisting of 200 consecutive out-patients between 25 and 65 years of age attending the Ophthalmic Department of the Gold Coast Hospital.

\section{Preliminary Investigation}

Of necessity, all the subjects in Group " $A$ " were males, but they were unselected in so far as all the clerical employees in the offices approached who came into the required age group were examined. They were all fit men and were carrying on their normal work. In each the corrected visual acuities were recorded, and a complete examination of the eyes was made, including ophthalmoscopy and slit-lamp microscopy. In addition, the intra-ocular tension was recorded with a Schiötz tonometer in each eye before and 45 minutes after the instillation of a 1 per cent. homatropine and 2 per cent. cocaine drop. The systolic and diastolic blood pressures were measured with a mercury manometer and in each subject with a diastolic pressure above $90 \mathrm{~mm} . \mathrm{Hg}$, the urine was examined. In all members of the group the corrected visual acuities were normal.

The records of ocular tension (Table I) show no unexpected features. Only two eyes, in the same subject, showed a basic tension greater than $25 \mathrm{~mm}$. Hg Schiötz. In each eye in this exceptional case the tension was $35 \mathrm{~mm}$. $\mathrm{Hg}$; it was not affected by the administration of a mydriatic and was probably due to rigidity of the globe.

TABLE I

INTRA-OCULAR TENSIONS IN CONTROL GROUP A

\begin{tabular}{lccccccccc}
\hline \multicolumn{1}{c}{ Intra-Ocular Tension (mm. Hg Schiötz) } & & $\begin{array}{c}\text { Before } \\
\text { Mydriatic }\end{array}$ & $\begin{array}{c}\text { After } \\
\text { Mydriatic }\end{array}$ \\
\hline Average & $\ldots$ & $\ldots$ & $\ldots$ & $\ldots$ & $\ldots$ & $\ldots$ & $\cdots$ & 24 & 26 \\
\hline Maximum & $\ldots$ & $\ldots$ & $\ldots$ & $\ldots$ & $\ldots$ & $\ldots$ & $\ldots$ & 35 & 35 \\
\hline Minimum & $\ldots$ & $\ldots$ & $\ldots$ & $\ldots$ & $\ldots$ & $\ldots$ & $\ldots$ & 16 & 18 \\
\hline
\end{tabular}

The blood pressures of both control groups are recorded comparatively in Table II (opposite), which shows that hypertension is relatively common in Africans of the social and economic status of the group under consideration. Forty-two of the 81 subjects in Group " $A$ " show hypertension, and in 38 there were visible changes of atherosclerosis in the retinal vessels.

\section{Clinical Findings}

The following findings are based on observations on 78 consecutive cases of primary glaucoma. Of these, seventy showed bilateral disease, a total of 148 glaucomatous eyes. The diagnosis has been made on a number of findings in each case and in the majority of the cases the disease was so advanced that there was no doubt as to the diagnosis. In others, the response of the intra-ocular tension to provocative tests was significant, and in a very few, reliable visual fields could be plotted. 
TABLE II

BLOOD PRESSURE RECORDS

\begin{tabular}{|c|c|c|c|c|c|c|c|c|c|c|c|c|c|}
\hline \multirow{4}{*}{ Group } & \multirow{4}{*}{$\begin{array}{l}\text { No. } \\
\text { of } \\
\text { Sub- } \\
\text { jects }\end{array}$} & \multicolumn{4}{|c|}{ Blood Pressure (mm. Hg Schiötz) } & \multicolumn{8}{|c|}{ Number Tested } \\
\hline & & \multirow{3}{*}{ Aystolic } & rage & & ange & & ystolic & ic B.P & & & iastoli & ic $\mathbf{B}$. & \\
\hline & & & \multirow{2}{*}{ Diastolic } & \multirow{2}{*}{ Systolic } & \multirow{2}{*}{ Diastolic } & \multicolumn{2}{|c|}{ over 200} & \multicolumn{2}{|c|}{$160-200$} & \multicolumn{2}{|c|}{ over 100} & \multicolumn{2}{|c|}{$90-100$} \\
\hline & & & & & & No. & $\%$ & No. & ${ }_{0}$ & No. & ${ }_{0}^{0}$ & No. & $\%$ \\
\hline Glaucoma & 78 & 156 & 84 & $100-254$ & $60-122$ & 8 & $10 \cdot 2$ & 26 & $33 \cdot 3$ & 24 & $30 \cdot 8$ & 28 & $35 \cdot 9$ \\
\hline Control A & 81 & 148 & 74 & $114-220$ & $58-118$ & 4 & $4 \cdot 9$ & 15 & $18 \cdot 5$ & 18 & $22 \cdot 2$ & 24 & $29 \cdot 6$ \\
\hline Control B & 200 & 136 & 76 & $90-198$ & 58-106 & 0 & 0 & 18 & 9 & 13 & 6 & 28 & 14 \\
\hline
\end{tabular}

The age distribution of the series is shown diagrammatically in the Figure, which shows that primary glaucoma is relatively common in younger adult Africans. The incidence is highest in the 41-50 decade but it would be unwise to draw

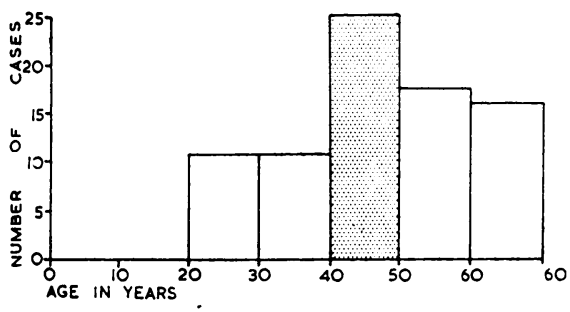

FIGURE.-Distribution by age groups of 78 cases of primary glaucoma in the Gold Coast. conclusions from the falling incidence after the age of 50 without a greater demographic knowledge of the people than is at present available.

From the histories obtained it would appear that the progress of the disease is insidious and as a rule painless; 67 per cent. of the patients showed advanced lesions when they were first seen, their attention having been drawn to the condition by an appreciable loss of vision in the second eye. A complaint of "occasional pain" was made by 17 per cent. In response to leading questions, 6 per cent. gave a history of "haloes" around lights, and 4 per cent. complained of transient blurring of vision especially in the early morning. It should be recorded that in the Gold Coast it is not uncommon to see patients whose vision is reduced to perception of light or less, with high tension and deep glaucomatous cupping of both optic discs; from the histories given it would appear that the onset is completely insidious. I have yet to see an African with primary glaucoma in a congestive phase, though congestive secondary glaucoma is common.

Of the 78 patients under consideration, 84 per cent. showed visual loss in one or both eyes when they were first seen, and the physical signs of glaucoma were so gross that the diagnosis was obvious. In 16 per cent. the vision was normal in both eyes, the diagnosis being suspected as a result of routine tonometry done on patients presenting themselves with symptoms suggestive of presbyopia. In some of the latter the initial tension was very high and showed gross variation after eserine or even after massage of the globe.

The average basic intra-ocular tension of 148 glaucomatous eyes was $41 \mathrm{~mm} . \mathrm{H}_{\mathrm{g}}$ 
Schiötz, these readings being recorded with the same tonometer as that used for the investigation of the Control Group "A." The range of the basic tension was $22-70 \mathrm{~mm}$. Hg Schiötz; in those eyes in which the initial tension was so high that a mydriatic might have been dangerous, an average fall of tension of $18 \mathrm{~mm}$. was found after the instillation of eserine or even after simple massage of the eye. In one eye in which the initial tension was $68 \mathrm{~mm}$. $\mathrm{Hg}$, Schiötz a fall of $36 \mathrm{~mm}$. was recorded after eserine.

Gross glaucomatous cupping of the discs was present in 61 per cent. of eyes, $\frac{0}{\circ}$ and to a lesser degree in a further 12 per cent. In the remainder no pathological $\frac{\bar{v}}{\bar{m}}$

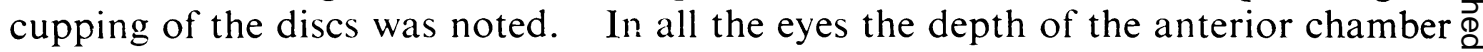
was normal.

Pathological changes, varying from slight irregularity of the arterial lumen to $\overrightarrow{0}$ gross attenuation of the arteries and venous congestion, were a fairly constant $\overrightarrow{\vec{\omega}}$ feature of the glaucoma cases, some degree of change being recorded in 76 of $\underset{\rho}{\omega}$ them. Blood pressures are recorded in Table II for comparison with the controlo group but it is worthy of note that changes were seen in the retinal vessels in a number of subjects in the absence of any marked elevation of diastolic blood $\vec{\circ}$ pressure.

In thirteen patients whose powers of co-operation were considered good enough $v$ for the results to be reliable, it was found possible to plot the visual fields. In all of them the disease was far advanced, the other clinical signs being so obvious 0 that the diagnosis was not in doubt. In three fields there were typical Ronne's $\frac{?}{0}$ steps, and in one the central field of the better eye showed a sector scotoma. In $\stackrel{\oplus}{-}$ the remainder there were only variable degrees of central field remaining, in non 8 more than $10^{\circ}$ from the fixation point. There was a normal visual acuity eve in the presence of gross field loss.

\section{Treatment}

It may be said categorically, that in the treatment of Gold Coast Africans $\frac{2}{\square}$ with primary glaucoma, early operation is obligatory. Any attempt to $\overrightarrow{\vec{O}}$ temporize with medical treatment, except as a pre-operative measure after 3 admission to hospital, results in the patient defaulting and presenting himself much later completely blind. This procedure can be varied only in highly educated urban subjects, and then with circumspection.

In all, 127 glaucomatous eyes were submitted to filtration operations (Table III).

TABLE III

SUMMARY OF SURGICAL TREATMENT

\begin{tabular}{|c|c|c|c|c|c|c|c|c|c|c|}
\hline \multirow{2}{*}{\multicolumn{6}{|c|}{ Operations }} & \multirow{3}{*}{$\begin{array}{c}\begin{array}{c}\text { Total } \\
\text { Patients }\end{array} \\
127\end{array}$} & \multicolumn{4}{|c|}{ Follow-up Period (mths) } \\
\hline & & & & & & & \multirow{2}{*}{$\frac{3}{115}$} & \multirow{2}{*}{$\begin{array}{c}6 \\
87\end{array}$} & \multirow{2}{*}{$\begin{array}{l}12 \\
51\end{array}$} & \multirow{2}{*}{$\frac{18}{32}$} \\
\hline Filtration & $\cdots$ & $\cdots$ & $\cdots$ & $\cdots$ & $\cdots$ & & & & & \\
\hline \multicolumn{3}{|c|}{ Trephine and Iridectomy } & $\ldots$ & $\ldots$ & $\ldots$ & 63 & 57 & 41 & 21 & 17 \\
\hline \multicolumn{5}{|c|}{ Anterior sclerectomy and Iridectomy } & $\ldots$ & 41 & 40 & 33 & 24 & 10 \\
\hline \multicolumn{5}{|c|}{ Anterior sclerectomy and Iridencleisis } & $\ldots$ & 18 & 13 & 9 & 6 & 5 \\
\hline \multicolumn{3}{|c|}{ Anterior sclerectomy } & $\cdots$ & $\cdots$ & $\cdots$ & 5 & 5 & 4 & 一 & - \\
\hline
\end{tabular}


Unfortunately, the follow-up of cases has not been impressive, since the majority of patients failed to attend after the first 6 months; it is difficult therefore to decide on the operation of choice. One of the principal complications in operations involving the iris in deeply-pigmented African eyes, has been the deposit of pigment on the anterior surface of the lens, and occasionally posterior synechiae due to a traumatic iridocyclitis. In the early post-operative period this is sufficient to reduce visual acuity. It is particularly marked with an iridencleisis but less so with an anterior sclerectomy and peripheral iridectomy. For this reason it has been found that the early post-operative results have been best after a classical trephine operation, in which the manipulation of the iris is done outside the anterior chamber.

As a result of following up a limited number of cases with an iridencleisis or iridectomy following anterior sclerectomy it appears that the pigment deposited at operation is subsequently absorbed and after a year causes no disability.

In one eye in which a $1 \cdot 5-\mathrm{mm}$. trephine had been performed an acute gonococcal conjunctivitis developed 6 months after operation. By the time this patient reported to hospital his eye was lost on account of a panophthalmitis. This must be regarded as a possible complication in the tropics where severe conjunctival infections are common.

In five cases the operation was limited to anterior sclerectomy without iridectomy or iridencleisis. Four of these have been followed up for 6 months and in each case there is satisfactory drainage and the tension is controlled. If this operation gives satisfactory results over longer periods it would appear to be the operation of choice in deeply pigmented eyes, as it avoids any interference with the iris. At the worst an iridencleisis can be performed at a second stage if anterior sclerectomy alone proves inadequate.

A number of eyes on which a peripheral iridectomy was done, were examined with a Goldmann contact lens. In all some posterior synechiae were seen 3 months after operation, and in most the edges of the iridectomy were completely adherent posteriorly. It is not at present possible to say whether this is permanent but the finding suggests that the iridectomy in such deeplypigmented eyes may be redundant.

In general, the mechanical results of all three operations were satisfactory in those cases which have been followed up for 18 months. Satisfactory drainage has continued with only one exception, attributable to incomplete haemostasis in a patient who was very restless at the original anterior sclerectomy; a second operation was done under general anaesthesia and the result is now satisfactory. It is worth recording that in no eye has there been any suggestion of keloid formation. This is a complication which appears to have received a publicity in the text-books which is out of proportion to its frequency in African eyes. 


\section{Comment}

It is impossible to make an accurate estimate of the incidence of primary glaucoma in the Gold Coast. Duke-Elder (1940) gives published figures for the percentages of cases of glaucoma reported from ophthalmic clinics all over the world; with few exceptions these range from 0.5 to 3 per cent. The Gold Coast percentage in the present series is within that range. The figures for blindness are only indicative and cannot be compared with those for countries where blind registration is in force. Proportionate figures for operations are affected by many unpredictable factors and are not really comparable between countries. In general it appears that, while primary glaucoma is a serious cause of blindness and morbidity in the Gold Coast, the incidence is not strikingly higher than in temperate climates, but is relatively commoner in the younger age groups.

There still appears to be a tendency to use the general term glaucoma in classifications of causes of blindness and morbidity in tropical countries. While the aetiology of "primary" glaucoma is still conjectural, that of secondary glaucoma is often obvious, and differentiation between the two is justifiable. Inclusion of both types under a single heading can only lead to confusion.

Diagnosis of primary glaucoma in the early stages in patients whose visual fields cannot be reliably investigated is often very difficult. It is necessary to rely on repeated tonometric readings with provocative doses of mydriatics in selected cases. In the writer's experience, the behaviour of the African eye during such investigations is comparable to that of other races; the assessment of the findings rests on general principles.

The association of clinical vascular degenerative changes in the retinal vessels with the occurrence of primary glaucoma is striking amongst Gold Coast Africans. Especially in comparison with Control Group "B", the incidence of vascular hypertension in the series of cases of primary glaucoma under review is high. It is not suggested that the glaucoma is secondary to hypertension or arterial degeneration, but rather that both result from similar primary factors.

I am indebted to Dr. L. G. Eddey, Director of Medical Services, Gold Coast, for his encouragement, and for permission to publish this paper.

\section{REFERENCES}

Boase, A. J. (1952). E. Afr. med. J., 29, 311.

BUDDEN, F. H. (1952). Brit. med. J., 1, 1248.

Chang, Hsiao-Lou (1951). Chin. med. J., 69, 341.

DoDDs, G. E. (1952). Brit. med. J., 1, 584.

DuKe-Elder, S. (1940). " "Text-book of Ophthalmology", vol. 3, p. $3328 . \quad$ Kimpton, London.

ELLIOT, R. H. (1920). " Tropical Ophthalmology”, p. 367. Frowde, Oxford University Press: Hodder and Stoughton, London. 